\title{
Diaphragm function in patients with cervical cord injury or prior poliomyelitis infection
}

\author{
C Sinderby ${ }^{1,5,6}$, J Weinberg ${ }^{3}$, L Sullivan ${ }^{1}, \mathbf{J ~ B o r g}^{4}$, L Lindström ${ }^{2}$ and A Grassino ${ }^{5,6}$ \\ ${ }^{1}$ Spinal Injuries Unit, Sahlgrenska Hospital, Gothenburg; ${ }^{2}$ Department of Clinical Data Processing, Sahlgrenska \\ Hospital, Gothenburg, Sweden; ${ }^{3}$ Department of Neurology, Söder Hospital, Stockholm, Sweden; ${ }^{4}$ Department of \\ Neurology, Karolinska Hospital, Stockholm, Sweden; ${ }^{5}$ Notre Dame Hospital, University of Montreal, Montreal, \\ Quebec, Canada and ${ }^{6}$ Meakins Christie Laboratories, McGill University, Montreal, Quebec, Canada
}

\begin{abstract}
Diaphragm function was evaluated in cervical cord injury patients (CCI), 1-3 years after injury $\left(\mathrm{CCI}_{1-3}\right)$ and 10 years or more after injury $\left(\mathrm{CCI}_{\geqslant 10}\right)$, as well as in a group of prior poliomyelitis infection patients (PPI), requiring intermittent positive pressure ventilation (IPPV) for about $6 \mathrm{~h}$ per night. Measurements included transdiaphragmatic pressure swings $(\Delta \mathrm{Pdi})$ at rest, during maximal inspiratory efforts against closed airways $\left(\Delta \mathrm{Pdi} \mathrm{i}_{\max }\right)$ and during sniff manoeuvres (ie maximal inhalation through the nose, $\Delta \mathrm{Pdi}_{\text {sniff }}$ ), vital capacity normalized to age and height $\left(\mathrm{VC}_{\% \text { pred }}\right)$, tidal volume $(\mathrm{Vt})$, relative inspiratory time $(\mathrm{Ti} / \mathrm{Ttot})$, breathing frequency $\left(\mathrm{f}_{\mathrm{b}}\right)$, and the tension-time index of the diaphragm $\left(\mathrm{TTdi}=\Delta \mathrm{Pdi} / \Delta \mathrm{Pdi} \mathrm{max}_{\max } \times \mathrm{Ti} / \mathrm{Ttot}\right)$. The median $\mathrm{VC}_{\% \text { pred }}$ was $50 \%$ in the $\mathrm{CCI}_{1-3}$ group and $57 \%$ in the $\mathrm{CCI}_{\geqslant 10}$ group, but only $28 \%$ in the PPI group. $\Delta \mathrm{Pdi}_{\max }$ values were similar for the $\mathrm{CCI}_{1-3}(11.8 \mathrm{kPa})$ and $\mathrm{CCI} \geqslant 10$ $(11.9 \mathrm{kPa})$ groups, but were lower $(7.1 \mathrm{kPa})$ in the PPI group. Due to the reduction in $\Delta \mathrm{Pdi}_{\max }$, the PPI group had higher $\Delta \mathrm{Pdi} / \Delta \mathrm{Pdi}_{\max }$ values than the CCI groups, however, the TTdi was similar amongst the different groups studied. A submaximal exercise test in five cervical cord injury patients and in five polio patients with similar $\Delta \mathrm{Pdi}_{\max }, \Delta \mathrm{Pdi}_{\text {sniff }}$ and TTdi values at rest revealed clear group differences with respect to force development, in that CCI patients showed significant increases in TTdi, while PPI demonstrated only minor changes. In CCI patients, an increase in ventilation was accompanied by an increase in $\Delta \mathrm{Pdi} / \Delta \mathrm{Pdi}_{\max }$ while in contrast, the PPI patients showed no increase in $\Delta \mathrm{Pdi} / \Delta \mathrm{Pdi}_{\max }$. We conclude that CCI patients, both recently and previously injured, have a similar maximal inspiratory force and are less impaired than the PPI patients. The TTdi at rest is similar in all groups, but the PPI patients react to inspiratory loads with little increases in TTdi, while the CCI patients increase their TTdi above fatiguing (0.15) levels. The different behaviours may be linked to loss of sensory pathways in the CCI patients.
\end{abstract}

Keywords: respiratory muscles; ventilatory failure; tetraplegia; poliomyelitis

\section{Introduction}

Neuromuscular disease often involves weakness of the respiratory muscles. If breathing strategies remain unaltered, this weakness presents an increasing load on the inspiratory muscles. Braun et al. ${ }^{1}$ suggested that patients with neuromuscular disorders who have paresis of the inspiratory muscles might fatigue their inspiratory muscles, which will then lead to further weakness, and subsequently to chronic hypercapnia. In these patients, periodic mechanical ventilation improved the patients' chronic hypercapnia, and was suggested to be due to rest of the respiratory muscles. ${ }^{1}$ More recent evidence derived from experiments on respiratory muscle loading in healthy humans, ${ }^{2}$ in

Correspondence: Christer Sinderby, Meakins Christie Laboratories, 3626 St. Urbain Street, McGill University, Montreal, Quebec, H2X 2P2, Canada obstructive sleep apnea patients, ${ }^{3}$ in awake and anaesthetized animals, ${ }^{4,5}$ and in patients with severe chronic obstructive ${ }^{6}$ pulmonary disease (COPD), ${ }^{1}$ suggests that subjects avoid fatigue of the respiratory muscles by hypoventilating. Afferent information from the over-exerted muscles may reduce the central drive in order to preserve muscle integrity.

The complex interplay between the time course of the force required to breathe and the maximal inspiratory force available is well described by the tension-time index of the diaphragm, TTdi. ${ }^{7,8}$ This index is the product of the transdiaphragmatic pressure expressed as a fraction of the maximal transdiaphragmatic pressure, and the duty cycle. The latter quantity represents the ratio between the time for inspiration ( $\mathrm{Ti}$ ) and the time for one total respiratory cycle (Ttot). In neuromuscular disorders, 
the force reserve (maximal force available minus force used ie maximal transdiaphragmatic pressure-tidal transdiaphragmatic pressure) of the diaphragm has clinical relevance. Neuromuscular patients with weak respiratory muscles are often referred to the Intensive Care Unit (ICU) because of ventilatory failure following a lung infection. ${ }^{9}$ Establishing the force reserve of the diaphragm is also of vital importance for patients who progressively deteriorate towards chronic respiratory insufficiency. In such patients, the clinical course may be decelerated, halted or even reversed by intermittent assisted ventilation. ${ }^{10,11,12}$ However, clear indications for the onset of treatment are not established.

Not all reductions in force reserve are expected to be compensated equally. If afferent information limits the force development, it is expected that cervical cord injury patients with abolition of sensory pathways may handle extra loads on inspiration differently than chronic poliomyelitis patients, where sensory pathways are intact.

This study set out to compare the pressure (force) developed by the diaphragm at rest and during exercise in two well-defined groups of patients with neuromuscular disorders: patients with cervical cord injuries (CCI) not receiving respiratory related treatment, and patients with prior poliomyelitis infection (PPI) treated with night-time assisted ventilation. In addition, we sought to evaluate the effects of time elapsed after injury on diaphragm function by comparing newly and chronically injured CCI patients. The respiratory response to exercise was compared in 5 CCI and 5 PPI patients with similar force reserves and resting diaphragm load. We wanted to identify the mechanical factors which operate in compensating the diaphragm during incipient ventilatory insufficiency.

\section{Methods}

\section{Patients}

Twenty-one male patients with motor deficits corresponding to clinically diagnosed complete cervical cord injuries at the $\mathrm{C} 5$ to $\mathrm{C} 8$ levels $(\mathrm{CCI})$, and six male patients with prior poliomyelitis infection (PPI) being treated chronically with intermittent positive pressure ventilation (IPPV) for approximately $6 \mathrm{~h}$ every night were included in this study. Eight CCI patients had been injured for 1 to 3 years $\left(\mathrm{CCI}_{1-3}\right)$ and thirteen $\mathrm{CCI}$ patients for 10 years or more $\left(C C I_{\geqslant 10}\right)$. Two PPI patients had received ICU treatment for acute respiratory insufficiency and one PPI patient had a history of chronic elevation of arterial carbon dioxide tension $\left(\mathrm{PaCO}_{2}\right)$ levels. All PPI patients had kyphoscoliosis (scoliosis angles ranged from $60^{\circ}$ to $120^{\circ}$ ) and three patients wore corsets. All patients gave their informed consent and the study was approved by the Ethical Committee at Sahlgrenska University Hospital, Gothenburg, Sweden.
Procedures and protocol

Gastric (Pga) and esophageal (Pes) pressures were obtained with two latex balloons attached to a modified quadruple-lumen Swan Ganz Pacing-TD catheter $(93-200 \mathrm{H}-7 \mathrm{~F}$, American Edwards Laboratories), $110 \mathrm{~cm}$ in length. ${ }^{13}$ Each balloon was $10 \mathrm{~cm}$ in length, $3.5 \mathrm{~cm}$ in circumference and $0.12-0.15 \mathrm{~mm}$ in thickness (AE Medical Corporation). A third balloon was attached (proximal end $6.5 \mathrm{~cm}$ below the distal end of the esophageal pressure balloon) to the catheter, and was used as an anchor. The catheter was connected to two differential pressure transducers (SCM-Screenmate-spezial, Erich Jaeger GmbH \& Co. $\mathrm{KG)}$ with the reference sides open to atmosphere. Ventilatory flow was measured at the mouth with a pneumotachograph (Jaeger Screenmate, 1/E 0586, resistance $36 \mathrm{~Pa} / 1 / \mathrm{s}$, Erich Jaeger $\mathrm{GmbH}$ \& Co.KG) mounted on a moveable lever. After analogue to digital conversion, the data was processed and stored in a digital computer (PDP-11/70, Digital Equipment Corporation). $\mathrm{Ti} / \mathrm{T}$ tot was calculated from ventilatory flow. Volume was obtained by the numerical integration of flow.

The transdiaphragmatic pressure was obtained by subtracting Pes from Pga. The thin lumen catheter used in the present study had a filtering effect on the recorded pressure signal, the dominating influence being that of a low-pass filter. ${ }^{14}$ The low-pass filtering due to the catheter's size was corrected by adding a portion of the pressure's time differential to the signal. In order to suppress the increased influence of noise due to this process, a low-pass filter was added. The cut-off frequencies of the two compensating filters were determined by minimizing the difference between the modified pressure signal and a 'true' pressure signal obtained at the same time through a thick walled wide lumen catheter $(1.2 \mathrm{~mm}$ internal diameter and of the same length as the modified Swan Ganz catheter). The characteristic frequencies obtained were $1.4 \mathrm{~Hz}$ for the differentiating filter and $8.7 \mathrm{~Hz}$ for the noise suppressing filter. Subtraction of the corrected pressure signal (modified Swan Ganz catheter) from the pressure signal obtained at the same time through a wide lumen catheter, during panting manoeuvres interrupted by coughs and sniffs, did not result in peak differences larger than $2 \%$ of the wide lumen catheter signal.

For each breath, the swing in transdiaphragmatic pressure was calculated as the difference between transdiaphragmatic pressure at end-inspiration and transdiaphragmatic pressure at end-expiration, and will subsequently be referred to as $\Delta \mathrm{Pdi}$. The maximal inspiratory $\Delta \mathrm{Pdi}\left(\Delta \mathrm{Pdi}_{\max }\right)$ was obtained by measuring maximal inspiratory efforts against a closed airway (Mueller maneouvre). $\Delta \mathrm{Pdi}_{\max }$ was calculated as the difference between the peak transdiaphragmatic pressure and the mean end-expiratory transdiaphragmatic pressure during tidal breathing. The sniff transdiaphragmatic pressure swing $\left(\Delta \mathrm{Pdi}_{\text {sniff }}\right)$ was obtained during maximally forced inspirations 
through the nose and was corrected for end-expiratory pressure, as described for $\Delta \mathrm{Pdi}_{\max }$. TTdi was calculated for each breath as the product of $\Delta \mathrm{Pdi} /$ $\Delta \mathrm{Pdi}_{\max }$ and $\mathrm{Ti} / \mathrm{Ttot}$.

Prior to the test, patients ate a small standardized breakfast. All tests were performed with the patients sitting comfortably in their own wheelchairs with no support for the arms. In three PPI patients, the test procedure was also performed with arm support.

The catheter was inserted into the nose, swallowed, and passed down into the esophagus to a distance of $30 \mathrm{~cm}$ from the nares. The anchoring balloon was then inflated and the catheter was withdrawn until it was anchored against the cardia of the stomach. The anchoring balloon was fixed in place by attaching a counterweight to the catheter just proximal to the nose.

In order to empty the esophageal and gastric balloons, a syringe was emptied until a negative pressure of $2 \mathrm{kPa}$ was obtained, ${ }^{15}$ since the Valsalva manoeuvre could not be performed by the CCI patients. Then, $0.5 \mathrm{ml}$ and $2.5 \mathrm{ml}$ of air were injected into the esophageal and the gastric balloons, respectively. ${ }^{15}$ The esophageal balloon technique was verified by the dynamic occlusion test in most patients, ${ }^{16}$ and invariably showed negligible differences between mouth and esophageal pressure swings.

Measurement of static respiratory parameters at rest Once the patients were at ease with the catheter, $\Delta \mathrm{Pdi}_{\max }$ and $\Delta \mathrm{Pdi}_{\text {sniff }}$ were measured. In order to improve the subjects' motivation, a video monitor was used to display the highest acquired $\Delta \mathrm{Pdi}_{\max }$ and $\Delta \mathrm{Pdi}_{\text {sniff }}$ which the patients could achieve from a series of at least three reproducible maximal attempts. Following these measurements, three vital capacity manoeuvres (VC) were performed at low levels of flow. The highest values were recorded and stored in the computer. Some PPI patients argued that they were not able to perform $\mathrm{VC}, \Delta \mathrm{Pdi}_{\max }$ and $\Delta \mathrm{Pdi}_{\text {sniff }}$ manoeuvres satisfactorily without arm support. These patients were therefore allowed to repeat the manoeuvres with arm support.

Measurement of dynamic respiratory parameters at rest Ten to $15 \mathrm{~min}$ following the maximal $\Delta$ Pdi tests, flow and pressures were recorded for approximately $1 \mathrm{~min}$ of tidal breathing. No attempts were made to standardize the breathing pattern during this period and the patients remained naive about these specific measurements.

\section{Measurement of dynamic respiratory parameters during exercise}

Five CCI and five PPI patients with similar $\Delta \mathrm{Pdi}_{\max }$ $(\mathrm{CCI}=8.5, \quad 6.0-11.6 \mathrm{kPa} ; \quad \mathrm{PPI}=7.1, \quad 6.2-8.7 \mathrm{kPa}$ median and range), $\Delta \mathrm{Pdi}_{\text {sniff }}(\mathrm{CCI}=5.1, \quad 3.9-8.0$; $\mathrm{PPI}=4.4, \quad 2.7-4.8)$, and resting TTdi values $(\mathrm{CCI}=0.07, \quad 0.06-0.08 ; \quad \mathrm{PPI}=0.07,0.06-0.08)$ performed a submaximal exercise test. These two groups will subsequently be referred to as $\mathrm{CCI}_{\text {exer }}$ and $\mathrm{PPI}_{\text {exer }}$. In order to determine the submaximal work load, subjects performed a pre-test consisting of a series of $4 \mathrm{~min}$ of arm or leg exercise with a crank rate of

Table 1 Median values and significance levels for $\mathrm{CCI}_{1-3}, \mathrm{CCI}_{\geqslant 10}$ and PPI group variables

\begin{tabular}{|c|c|c|c|c|c|c|}
\hline & $\begin{array}{l}C C I_{1-3} \\
\text { Median }\end{array}$ & $\begin{array}{l}C C I_{\geqslant 10} \\
\text { Median }\end{array}$ & $\begin{array}{c}\text { PPI } \\
\text { Median }\end{array}$ & $C C I_{1-3}-C C I_{\geqslant 10}$ & $\mathrm{CCI}_{1}{ }_{3}-\mathrm{PPI}$ & $C C I_{\geqslant 10^{-}} P P I$ \\
\hline Age (years) & 26 & 41 & 46 & $* *$ & $* *$ & $* *$ \\
\hline Height $(\mathrm{cm})$ & 180 & 185 & 168 & ns & $* *$ & $* *$ \\
\hline Weight (kg) & 68 & 70 & 64 & ns & ns & ns \\
\hline Time after injury/ & & & & & & $* * *$ \\
\hline infection (years) & 2 & 17 & 42 & ns & $* *$ & \\
\hline Level of injury & 6.5 & 6.5 & & ns & - & ns \\
\hline $\mathrm{Vt}(\mathrm{I})$ & 0.6 & 0.6 & 0.4 & ns & ns & $* * *$ \\
\hline VC (I) & 2.8 & 3.3 & 1.3 & ns & $* *$ & $* * *$ \\
\hline $\mathrm{VC}_{\% \text { pred }}(\%)$ & 50 & 57 & 28 & ns & $* *$ & $* *$ \\
\hline $\mathrm{Pdi}_{\max }(\mathrm{kPa})$ & 11.8 & 11.9 & 7.1 & ns & $*$ & $*$ \\
\hline $\mathrm{Pdi}_{\text {sniff }}(\mathrm{kPa})$ & 8.0 & 7.9 & 4.4 & ns & $*$ & ns \\
\hline$\Delta \mathrm{Pdi}(\mathrm{kPa})$ & 1.2 & 1.4 & 1.4 & ns & ns & $*$ \\
\hline$\Delta \mathrm{Pdi} / \Delta \mathrm{Pdi}_{\max }$ & 0.11 & 0.13 & 0.17 & ns & $*$ & ns \\
\hline $\mathrm{Ti}(\mathrm{s})$ & 1.6 & 1.6 & 1.2 & ns & ns & ns \\
\hline Ttot $(\mathrm{s})$ & 3.8 & 3.6 & 2.8 & ns & ns & ns \\
\hline Ti/Ttot & 0.42 & 0.45 & 0.39 & ns & ns & ns \\
\hline TTdi & 0.05 & 0.06 & 0.07 & ns & ns & ns \\
\hline
\end{tabular}

${ }^{*} P<0.05,{ }^{* *} P<0.01,{ }^{* * *} P<0.001$. Abbreviations: $\mathrm{CCI}=$ cervical cord injuries; $\mathrm{CCI}_{1-3}=1-3$ year after injury; $\mathrm{CCI} \geqslant 10=10$ years or more after injury; $\mathrm{PPI}=$ prior polio infection; $\mathrm{Vt}=$ tidal volume at normal breathing; $\mathrm{VC}=$ vital capacity; $\mathrm{VC} \%$ pred $=$ vital capacity in per cent of predicted value; $\Delta \mathrm{Pdi}_{\max }=$ the highest transdiaphragmatic pressure swing obtained during a maximal inspiratory manoeuvre against a closed airway; $\Delta \mathrm{Pdi}_{\text {sniff }}=$ the highest transdiaphragmatic pressure swing obtained during a maximal forced inspiration through the nose; $\Delta \mathrm{Pdi}=$ transdiaphragmatic pressure swing during a normal tidal breath; $\mathrm{Ti}=$ inspiratory time; $\mathrm{Ttot}=$ total time for one breath; $\mathrm{TTdi}=$ the product of $\Delta \mathrm{Pdi} / \Delta \mathrm{Pdi} \max$ and $\mathrm{Ti} / \mathrm{Tt}$ tot 
$60 \mathrm{rpm}$. The patient was given a 5 min rest between each work load. The initial work load was 10 watt $(\mathrm{W})$ and the work load was successively increased by $10 \mathrm{~W}$ until the $4 \mathrm{~min}$ period could no longer be endured. The highest load that could be sustained for 4 min will subsequently be referred to as $\mathrm{Wmax}$. The degree of perceived effort of respiration and work in the extremities was determined by the subject on a 6-20 degree rating scale of perceived exertion (RPE) every $30 \mathrm{s.}^{17}$

One week following the pre-test, subjects returned to perform the main protocol which included the recording of respiratory parameters. Before the start of the exercise test, each subject sat still while holding his hands on the arm ergometer. The patient was provided with a noseclip and breathed through the pneumotachograph. In patients with poor grip function the hands were secured onto the hand-grips with an elastic bandage. The exercise test started with $30 \mathrm{~s}$ of breathing at rest, and was followed by a $120 \mathrm{~s}$ warm-up period at approximately $20 \%$ of $\mathrm{Wmax}$. The load was then increased to Wmax, and the exercise continued until exhaustion.

\section{Electromyographic (EMG) measurements}

Qualitative determination of voluntary intercostal muscle EMG activity was performed with a bipolar surface EMG electrode. The electrode was successively positioned in the first to the seventh intercostal space in the midclavicular line parasternally. For each intercostal space, the patients were urged to make at least three maximal inspirations. As a criterion for the loss of voluntary muscle activity, we used total absence of phasic inspiratory myoelectric activity.

\section{Statistical methods}

Group values are presented as medians and ranges. Comparison of the different groups was performed by nonparametric statistics (Wilcoxon rank-sum test). To analyze the relationships between the different variables, we used simple linear and multiple regression analyses. Statistical significance was expected if the probability for rejection of the null hypothesis exceeded $95 \%$ (ie $P<0.05$ ).

\section{Results}

Group median anthropometric data and median values of $\Delta \mathrm{Pdi}_{\text {max }}, \Delta \mathrm{Pdi}_{\text {sniff }}, \Delta \mathrm{Pdi} / \Delta \mathrm{Pdi}_{\max }, \mathrm{Ti}, \mathrm{Ttot}, \mathrm{Ti} / \mathrm{T}$ tot, $\mathrm{VC}$ and $\mathrm{VC}_{\% \text { pred }}$ ( $\mathrm{VC}$ related to height and age) obtained at rest for $\mathrm{CCI}_{1-3}, \mathrm{CCl}_{\geqslant 10}$ and PPI patients are presented in Table 1.

\section{Static respiratory parameters}

$\mathrm{VC}_{\% \text { pred }}$ values were reduced to $50 \%, 57 \%$ and $28 \%$ in the $\mathrm{CCI}_{1.3}, \mathrm{CCI}_{\geqslant 10}$, and PPI groups, respectively. $\Delta \mathrm{Pdi}_{\text {max }}$, and $\Delta \mathrm{Pdi}_{\text {sniff }}$ values were similar for the $\mathrm{CCI}_{1-3}$, and $\mathrm{CCI} \geqslant 10$ groups, but significantly lower for the PPI patients (Table 1). The contribution of $\Delta$ Pes and $\Delta \mathrm{Pga}$ to $\Delta \mathrm{Pdi}_{\max }$ in each subject is illustrated in

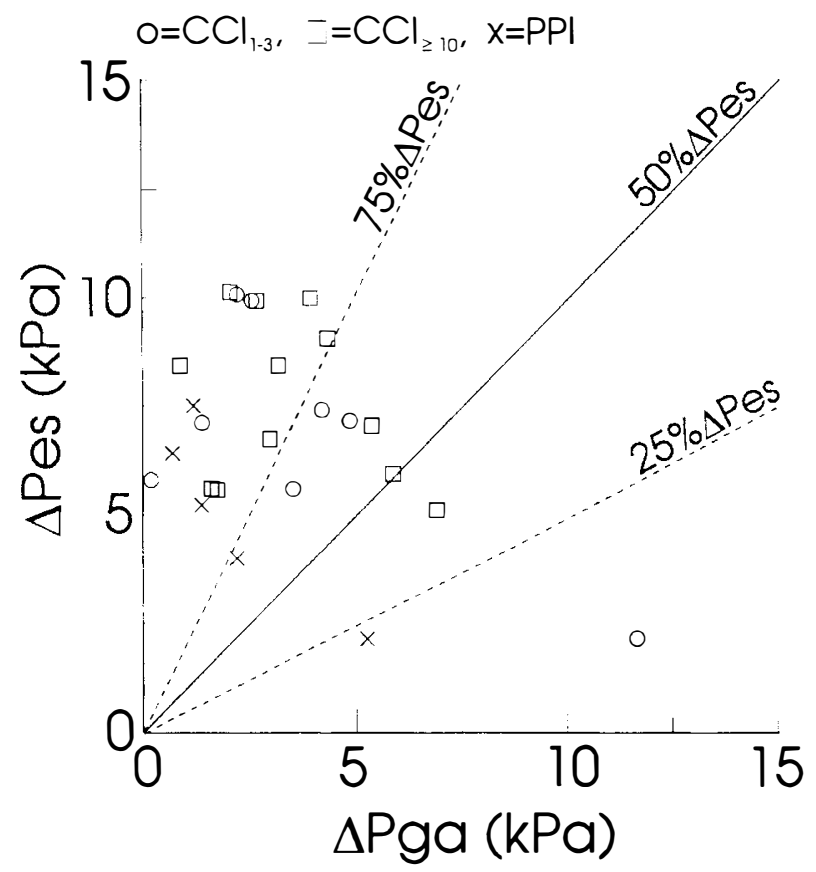

Figure $1 \Delta \mathrm{Pes}$ and $\Delta \mathrm{Pga}$ contribution to $\Delta \mathrm{Pdi}_{\max }$ in $\mathrm{CCI}_{13}$ (circles), $\mathrm{CCI}_{\geqslant 10}$ (squares) and in PPI (crosses) patients. In most patients, $\Delta \mathrm{Pdi}_{\max }$ was dominated by the increase in $\Delta$ Pes. Although, in three patients, $(2 \mathrm{CCI}$ and $1 \mathrm{PPI}$ ) the $\Delta \mathrm{Pga}$ contribution to $\Delta \mathrm{Pdi}_{\max }$ was higher than the $\Delta \mathrm{Pes}$. In the two CCI patients, the higher $\Delta$ Pga values could be explained by a reduction in abdominal compliance. However, in the PPI patient no such explanation was found indicating that $\Delta \mathrm{Pdi}_{\max }$ mainly consisted of an expulsive abdominal contraction

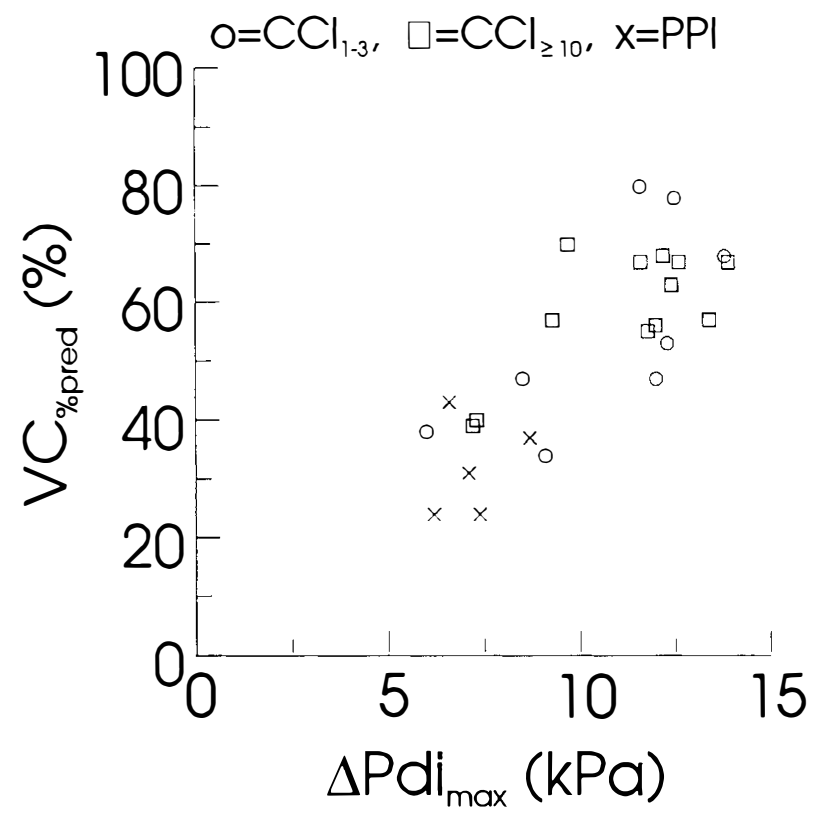

Figure 2 In all patients $\mathrm{VC}_{\% \text { pred }}$ was dependent of $\Delta \operatorname{Pdi}_{\max }(r=0.77)$ and followed the regression line $\mathrm{VC}_{\% \text { pred }}=2.0+\Delta \mathrm{Pdi}_{\max } \times 4.9 \quad(P<0.0001) . \quad$ Circles $=\mathrm{CCI}_{1-3}$, squares $=\mathrm{CCI}_{\geqslant 10}$ and crosses $=$ PPI patients 
Figure 1. In the PPI patients, who argued that their performance of $\mathrm{VC}, \Delta \mathrm{Pdi}_{\max }$ and $\Delta \mathrm{Pdi}_{\text {sniff }}$ were improved with arm support, the use of the arms during these manoeuvres did not reveal any substantial benefit.

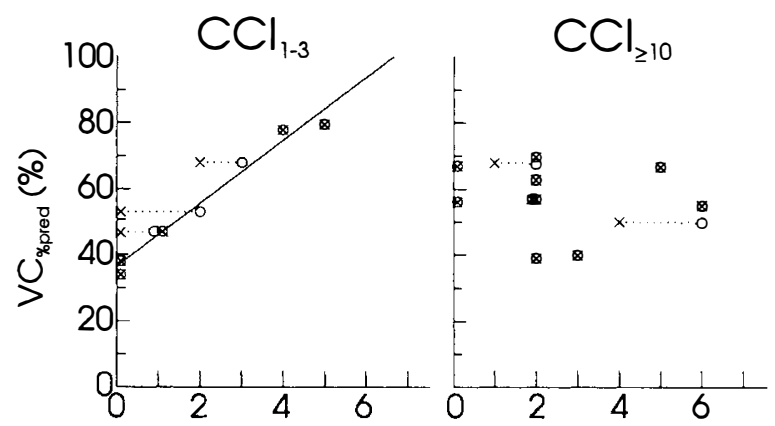

Number of intercostal spaces with phasic EMG activity

Figure 3 The left panel of the diagram illustrates the high correlation $(r=0.98)$ between the $\mathrm{VC}_{\% \text { pred }}$ and the number of left (circles) and right (crosses) side intercostal muscles with maintained inspiratory EMG activity in $\mathrm{CCI}_{1-3}$ patients. The regression line indicates that $\mathrm{VC}_{\%}$ pred will be between 35 to $40 \%$ in patients with no intercostal muscle function and $100 \%$ in patients with muscle function in seven intercostal spaces, as determined by EMG. No such relationship was found in $\mathrm{CCI}_{\geqslant 10}$ patients as illustrated in the right panel

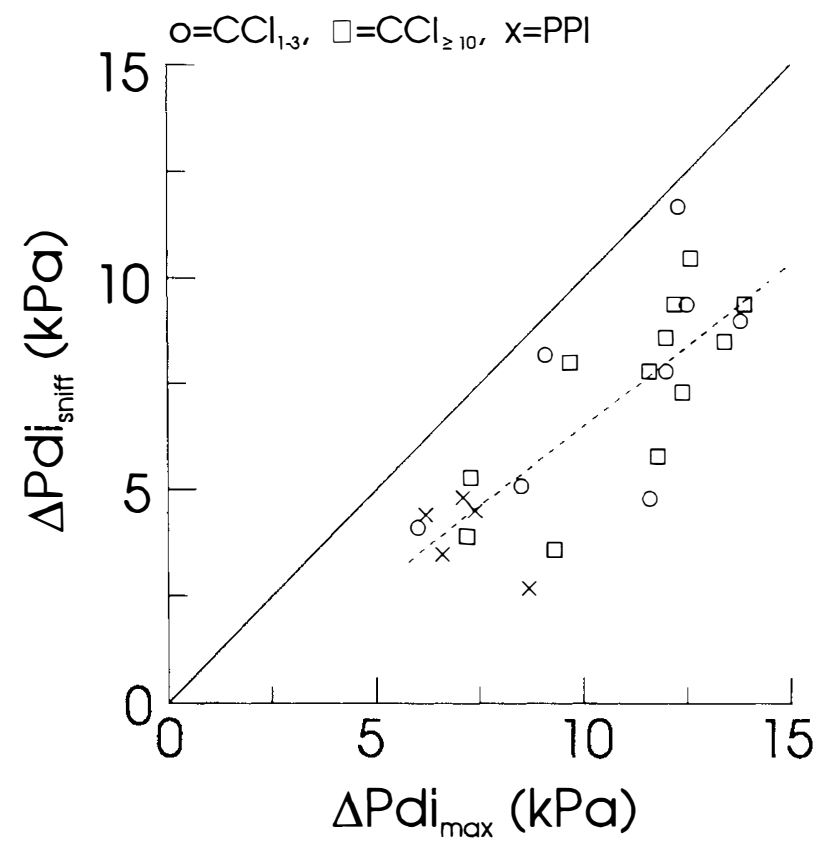

Figure 4 Correlation between $\Delta \mathrm{Pdi}_{\max }$ and $\Delta \mathrm{Pdi}_{\text {sniff }}$ $(r=0.79)$. The progressive increase in the difference between the regression (dashed) line and the line of identity (solid) indicates that, in the studied interval, there is an increase in difference between the two measures with increasing diaphragmatic force. $\mathrm{CCI}_{1-3}=$ circles, $\mathrm{CCI} \geqslant 10=$ squares and PPI $=$ crosses
In all patients, the $\mathrm{VC}_{\% \text { pred }}$ was dependent on $\Delta \mathrm{Pdi}_{\max }(r=0.77)$, as illustrated in Figure 2 . In $\mathrm{CCI}_{1-3}$ patients, $\mathrm{VC}_{\% \text { pred }}$ strongly correlated $(\mathrm{R}=0.98)$ to the number of intercostal spaces producing EMG activity, as illustrated in Figure 3 (left panel). In the patients with older injuries, $\mathrm{CCI} \geqslant 10$, the strong dependence of $\mathrm{VC}_{\% \text { pred }}$ on maintained intercostal function was no longer evident (Figure 3, right panel). No correlation was found between $\mathrm{VC}_{\%}$ pred and the clinically determined motor level of lesion in any of the two CCI groups. $\Delta \mathrm{Pdi}_{\max }$ correlated weakly $(r=0.57)$ with the motor lesion level in the $\mathrm{CCI} \geqslant 10$ group, but not in the $\mathrm{CCI}_{1-3}$. For all the data (ie pooling both $\mathrm{CCI}$ groups and the PPI group), the correlation between $\Delta \mathrm{Pdi}_{\max }$ and $\Delta \mathrm{Pdi}_{\text {sniff }}$ was high $(r=0.79)$ as depicted in Figure 4. $\Delta \mathrm{Pdi}_{\text {sniff }}$ was always smaller than $\Delta \mathrm{Pdi}_{\max }$ by a magnitude of 15 to $20 \%$.

Dynamic respiratory parameters measured at rest The median TTdi values were similar for the three groups, ranging from 0.05 to 0.07 (Table 1). Compared to PPI patients, the median $\Delta \mathrm{Pdi} / \Delta \mathrm{Pdi}$ max ratio was $35 \%$ lower in the $\mathrm{CCI}_{1-3}$ patients and $24 \%$ lower in the $\mathrm{CCI} \geqslant 10$ patients. The lowest Ttot was found in the PPI group, giving a median $\mathrm{f}_{\mathrm{b}}$ of 22 breaths $/ \mathrm{min}$, compared to 16 and 17 breaths/min, respectively, in the $\mathrm{CCI}_{1-3}$ and $\mathrm{CCI} \geqslant 10$ patients. A similar pattern was found for $\mathrm{Ti}$ and was confirmed by a very high correlation between $\mathrm{Ti}$ and Ttot $(r=0.94)$. No significant differences in $\mathrm{Vt}, \Delta \mathrm{Pdi}$, and $\mathrm{Ti} / \mathrm{T}$ tot were found between the $\mathrm{CCI}_{1-3}$ and $\mathrm{CCI} \geqslant 10$ and PPI groups.

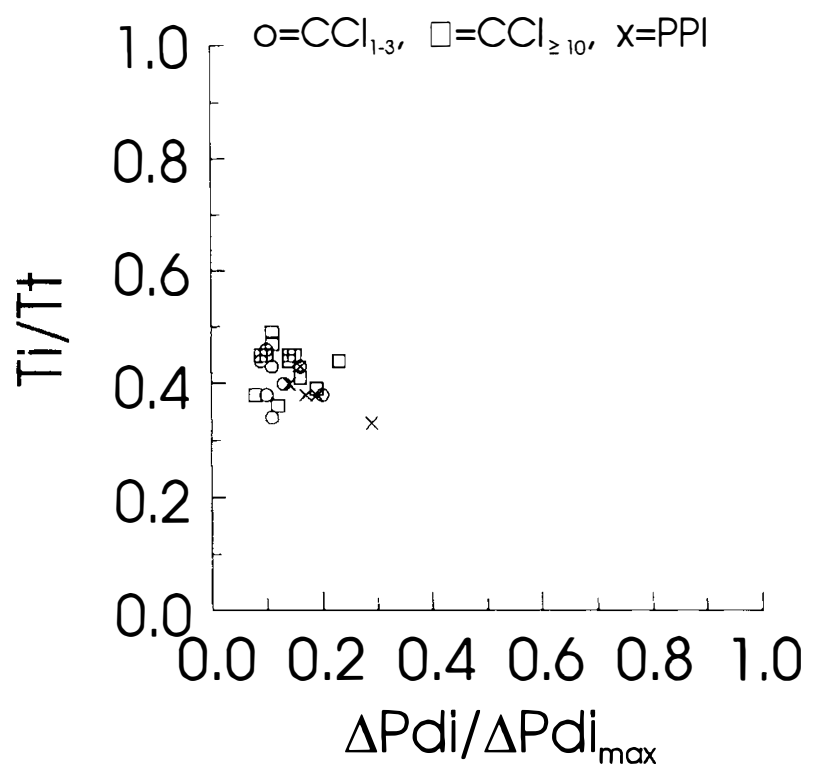

Figure 5 The contribution of $\Delta \mathrm{Pdi} / \Delta \mathrm{Pdi}_{\max }$ and $\mathrm{Ti} / \mathrm{T}$ tot to TTdi in the $\mathrm{CCI}_{1-3}$ (circles), $\mathrm{CCI}_{\geqslant 10}$ (squares) and in the PPI (crosses) patients. As depicted in the diagram no clear distinctions were found between the CCI groups and ventilator treated PPI group 
Figure 5 , depicting the $\mathrm{Ti} / \mathrm{T}$ tot and $\Delta \mathrm{Pdi} / \Delta \mathrm{pdi}_{\max }$ contributions to the TTdi, illustrates that several $\mathrm{CCI}_{1-3}$ and $\mathrm{CCI} \geqslant 10$ patients had values overlapping those of the PPI patients.
Dynamic respiratory parameters measured during exercise

In contrast to the results of dynamic respiratory parameters measured at rest, the exercise test revealed
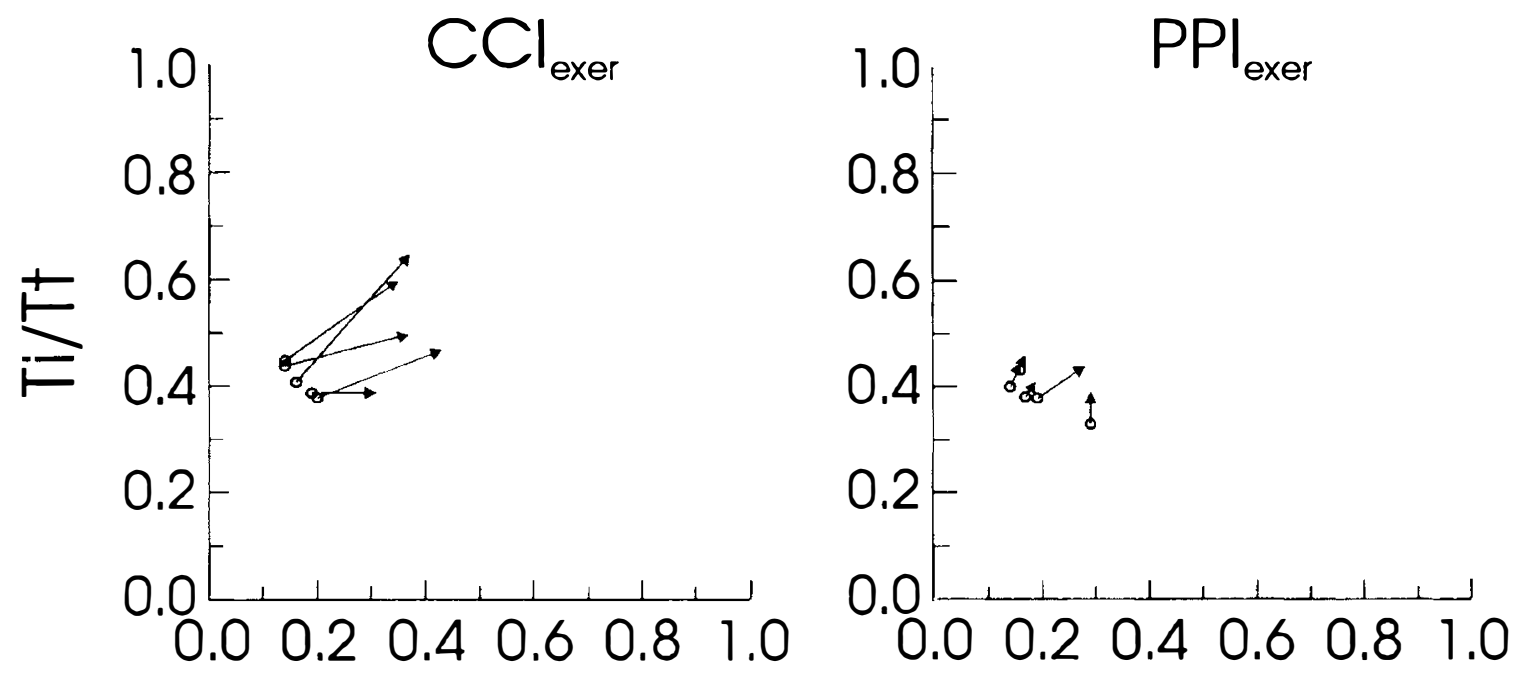

\section{$\Delta \mathrm{Pdi} / \Delta \mathrm{Pdi} \mathrm{max}_{\max }$}

Figure 6 In the $\mathrm{CCI}_{\text {exer }}$ group (left panel), the changes in $\Delta \mathrm{Pdi} / \Delta \mathrm{Pdi} \mathrm{i}_{\max }$ and $\mathrm{Ti} / \mathrm{T}$ tot from rest to the end of exercise resulted in clear increases in TTdi. Corresponding changes in $\Delta \mathrm{Pdi} / \Delta \mathrm{Pdi}_{\max }$ and $\mathrm{Ti} / \mathrm{T}$ tot were not found in the $\mathrm{PPI}$ exer group (right panel) who only showed minor changes in TTdi

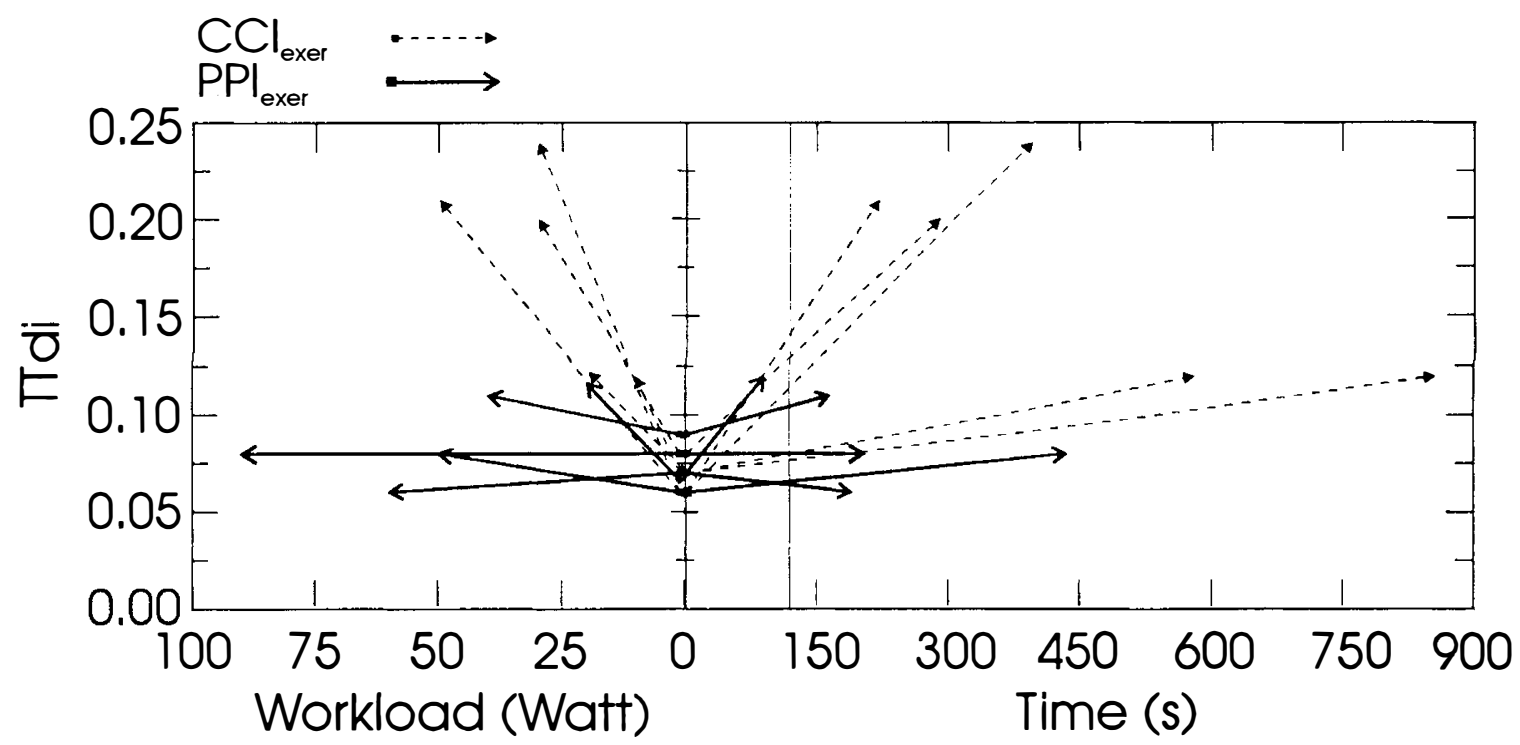

Figure 7 Description of the excercise-induced changes in TTdi from rest to end of exercise, in relation to workload and time of exercise in the $\mathrm{CCI}_{\text {exer }}$ (dashed lines and circles) and $\mathrm{PPI}_{\text {exer }}$ (solid lines and crosses) patients. The vertical solid line at $120 \mathrm{~s}$ indicates the end of the warm-up period 
clear differences between $\mathrm{CCI}_{\text {exer }}$ and $\mathrm{PPI}_{\text {exer }}$ patients for TTdi. Figure 6 depicts the contribution of $\Delta \mathrm{Pdi} /$ $\Delta \mathrm{Pdi}_{\max }$ and $\mathrm{Ti} / \mathrm{T}$ tot during $1 \mathrm{~min}$ of rest and during the last $30 \mathrm{~s}$ of exercise in the $\mathrm{CCI}_{\text {exer }}$ patients (left panel) and the $P P I_{\text {exer }}$ patients (right panel). During exercise, all the $\mathrm{PPI}_{\text {exer }}$ patients except one showed little or no increase in $\Delta \mathrm{Pdi} / \Delta \mathrm{Pdi}_{\max }$, while all the $\mathrm{CCI}_{\text {exer }}$ patients showed clear increases in $\Delta \mathrm{Pdi} /$ $\Delta \mathrm{Pdi}_{\max }$. Each patient's change in TTdi from rest to the end of exercise, in relation to endurance time and workload, is illustrated in Figure 7.

Compared to the $\mathrm{CCI}_{\text {exer }}$ patients, the $\mathrm{PPI}_{\text {exer }}$ patients seemed to have higher perceived respiratory efforts than perceived efforts in the extremities. The $\Delta \mathrm{Pdi} / \Delta \mathrm{Pdi}_{\max }$ obtained at end of exercise was not related to the perceived respiratory effort obtained during the pre-test (right panel of Figure 8). However, the perceived respiratory effort was inversely related (not significant for the CCI patients) to the change in $\Delta \mathrm{Pdi} / \Delta \mathrm{Pdi}_{\max }$ from rest to end of exercise, as depicted in the left panel of Figure 8. During exercise, $\mathrm{CCI}_{\text {exer }}$ patients demonstrated higher increases in $\Delta \mathrm{Pdi}$ $\Delta \mathrm{Pdi}_{\max }$ with a perception of lower respiratory effort, compared to the $\mathrm{PPI}_{\text {exer }}$ patients.

Despite the differences in development of $\Delta \mathrm{Pdi} /$ $\Delta \mathrm{Pdi}_{\max }$ during exercise in the $\mathrm{CCI}_{\text {exer }}$ and the $P P \mathrm{I}_{\text {exer }}$ groups, no clear differences were observed between the groups regarding changes in $\mathrm{f}_{\mathrm{b}}, \mathrm{Vt}$ and mean inspiratory flow $(\mathrm{Vt} / \mathrm{Ti})$. As illustrated in Figure 9a and $9 \mathrm{~b}$ (left panels), $\mathrm{CCI}_{\text {exer }}$ and $\mathrm{PPI}_{\text {exer }}$ patients demonstrated clear increases in $\mathrm{f}_{\mathrm{b}}$ and $\mathrm{Vt} / \mathrm{Ti}$ during exercise. In each group, the patient with the highest $\mathrm{Vt} / \mathrm{Ti}$ at rest, showed a reduced $\mathrm{Vt}$ during exercise. The right panels of Figure $9 \mathrm{a}$ and $\mathrm{b}$ illustrate that, during exercise, the increase in $\mathrm{Vt}$ and $\mathrm{Vt} / \mathrm{Ti}$ was accompanied by increases in the $\Delta \mathrm{Pdi} / \Delta \mathrm{Pdi}_{\max }$ in the

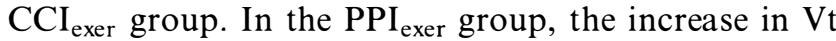
and $\mathrm{Vt} / \mathrm{Ti}$ was not associated with an increase in $\Delta \mathrm{Pdi} /$ $\Delta \mathrm{Pdi}_{\max }$. From rest to the end of exercise, most PPI $\mathrm{Pxer}$ patients demonstrated shifts in the major axis of the Pes-Pga curve, as illustrated in Figure 10 for one breath obtained at rest and one breath obtained during the last minute of exercise in one PPI ${ }_{\text {exer }}$ patient.

\section{Discussion}

The $\Delta \mathrm{Pdi}_{\max }$ values obtained during a Mueller manoeuvre in normal male subjects range from 10 to $14 \mathrm{kPa}$. The median $\Delta \mathrm{Pdi}_{\max }$ values obtained for the cervical cord injured patients $\left(\mathrm{CCI}_{1-3}=11.8 \mathrm{kPa}\right.$ and $C C I_{\geqslant 10}=11.9 \mathrm{kPa}$ ) indicate that the diaphragmatic force in most CCI patients is close to normals. However, about $20 \%$ of the CCI patients have

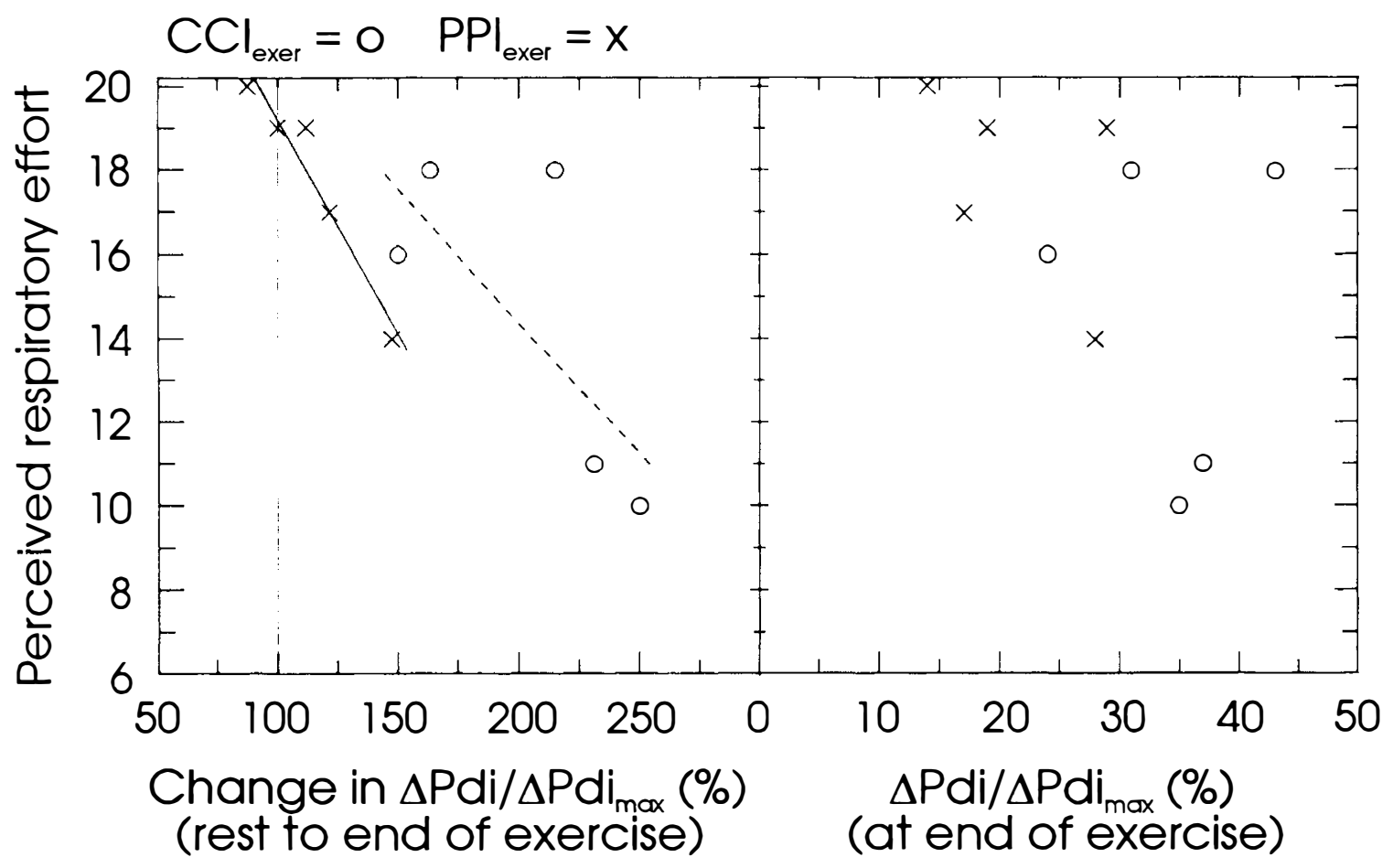

Figure 8 As depicted in the left panel, the PPI patients (crosses) showed an inverse relationship between the perceived respiratory effort, as reported during the last minute of exercise at $\mathrm{Wmax}$ in the pre-test, and the change in $\Delta \mathrm{Pdi} / \Delta \mathrm{Pdi}$ max ratio $\left(100 \%\right.$ indicate resting level) in the second test. In CCI patients with similar TTdi at rest (circles), the increases in $\Delta \mathrm{Pdi} / \Delta \mathrm{Pdi} \mathrm{i}_{\text {max }}$ were substantially higher for any given recording of perceived respiratory effort, compared to the PPI group. The right panel show that no correlation was found between the perceived respiratory effort in and the $\Delta \mathrm{Pdi} / \Delta \mathrm{Pdi} \mathrm{i}_{\max }$ at the end of exercise, suggesting that the RPE scale relates better to the changes in force than the actual force developed 

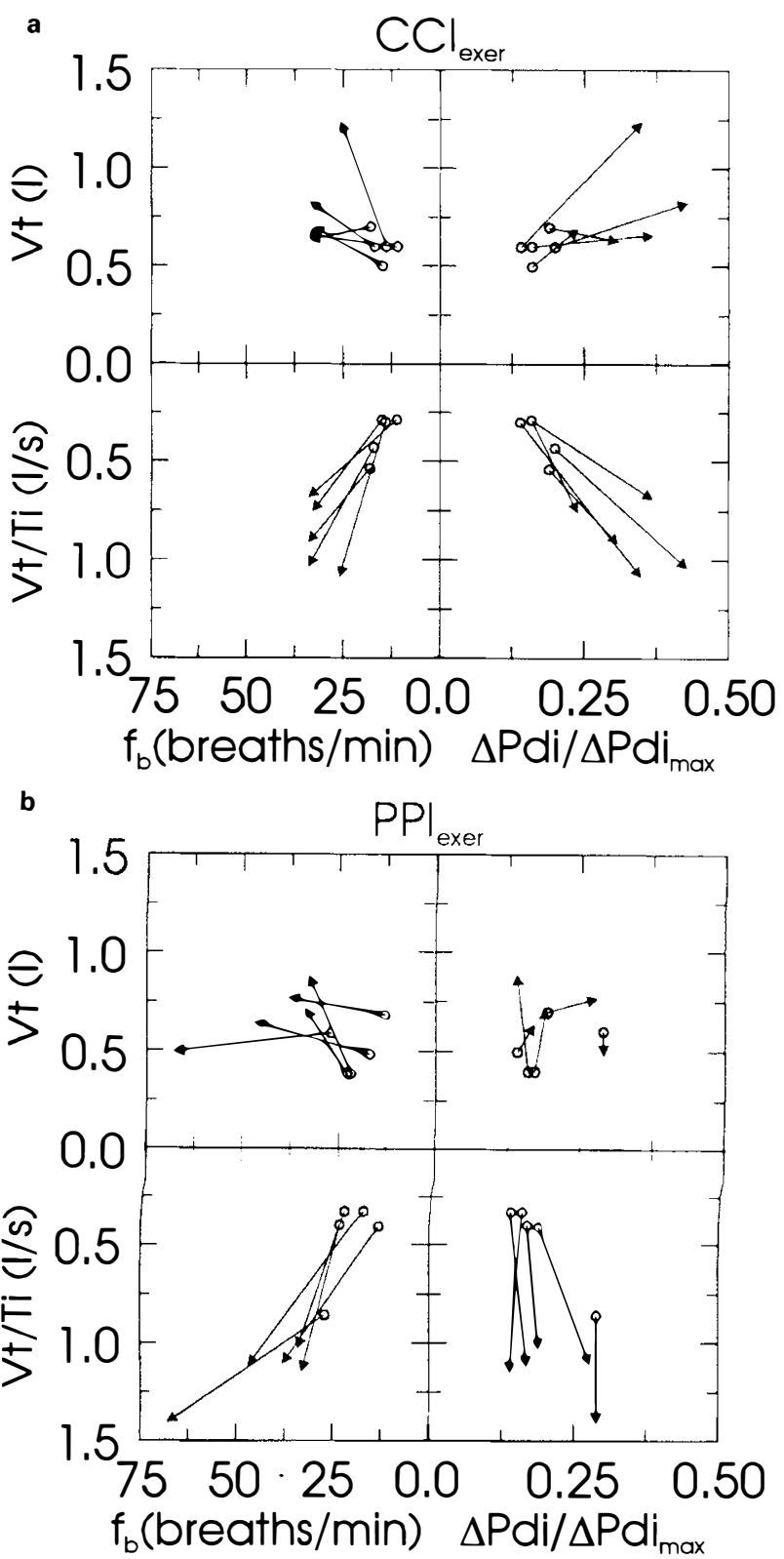

Figure 9 (a, b) The ventilatory response to exercise was similar in the $\mathrm{CCI}_{\text {exer }}$ (a, left panels) and $\mathrm{PPI}_{\text {exer }}$ (b, left panels) regarding changes in $\mathrm{Vt}, \mathrm{Vt} / \mathrm{Ti}$, and $\mathrm{f}_{\mathrm{b}}$. However, in the $\mathrm{CCI}_{\text {exer }}$ group (a, right panels) the increase in $\mathrm{Vt}$ and $\mathrm{Vt} /$ $\mathrm{Ti}$ were related to increases in $\Delta \mathrm{Pdi} / \Delta \mathrm{Pdi}_{\max }$ ratios. In contrast, increases in $\mathrm{Vt}$ and $\mathrm{Vt} / \mathrm{Ti}$ in the $\mathrm{PPI}_{\text {exer }}$ group (b, right panels) were not characterized by such an increase in $\Delta \mathrm{Pdi} / \Delta \mathrm{Pdi}_{\max }$

reduced $\Delta \mathrm{Pdi}_{\max }$ and $\Delta \mathrm{Pdi}_{\text {sniff }}$ values comparable to those of the PPI patients. In the PPI patients, the median $\Delta \mathrm{Pdi}_{\max }$ value of 7.1 denotes a clear reduction (notice that the median age is higher in the PPI group). The contribution of $\Delta \mathrm{Pes}$ and $\Delta \mathrm{Pga}$ to $\Delta \mathrm{Pdi}_{\max }$ was dominated by $\Delta$ Pes similar to the findings reported for the Mueller manoeuvre in patients with pulmonary

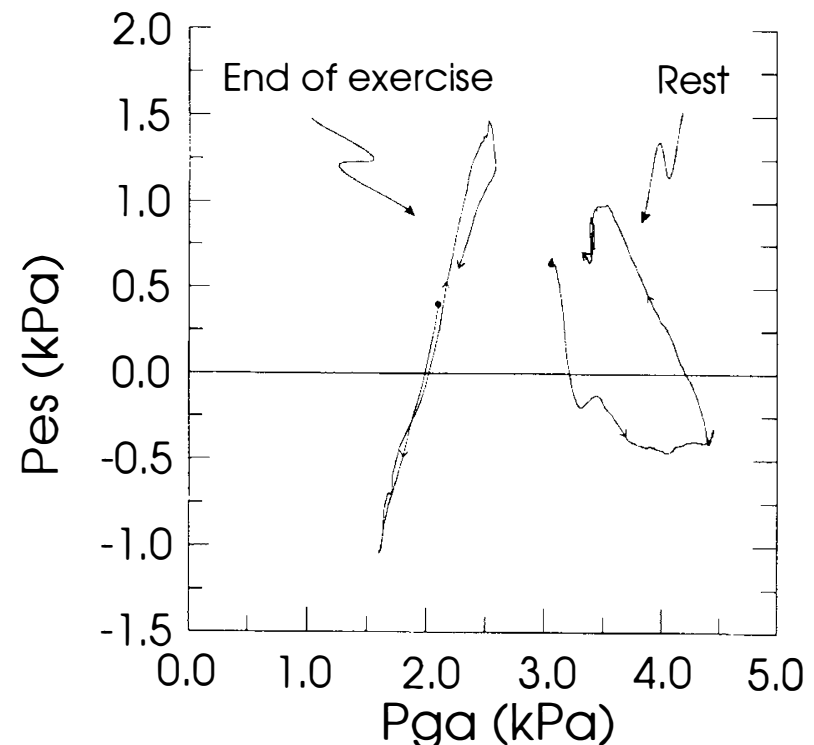

Figure 10 Illustration of a typical shift in the major axis of the Pes-Pga curve. As illustrated, the proportional relationship between Pes and Pga found at rest is replaced by an inversely proportional relationship during exercise with a clear reduction in the loop hysteresis. Also, the mean absolute Pga is decreased and the peak Pes values are higher during exercise. Solid circles indicate start of the loop

fibrosis. ${ }^{18}$ One PPI and two CCI patients showed higher $\Delta \mathrm{Pga}$ than $\Delta \mathrm{Pes}$ contribution to $\Delta \mathrm{Pdi}_{\max }$ as shown in Figure 1. One of the CCI patients used an abdominal binder, the other had undergone an anterior rhizotomy, giving signs of decreased abdominal compliance. No support for such an explanation was found for the PPI patient, indicating that he probably performed the Mueller manoeuvre in combination with an abdominal expulsive effort.

Miller et $a .^{24}$ reported a mean $\Delta$ Pdi $_{\text {sniff value of }}$ $14 \mathrm{kPa}$ in normal male subjects, which is clearly higher than our findings of $8 \mathrm{kPa}$ in the CCI groups. In contrast to the results in our study, the $\Delta \mathrm{Pdi}_{\text {sniff values }}$ in their study exceeded the $\Delta \mathrm{Pdi}_{\max }$ values obtained during a Mueller manoeuvre. However, in the study of Miller et $a l,{ }^{24}$ the $\Delta$ Pga contribution to the $\Delta$ Pdi was clearly lower during $\Delta \mathrm{Pdi}_{\max }$ (Mueller manoeuvre)

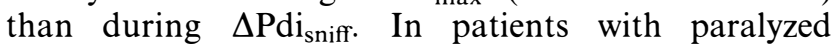
abdominal muscles, as the CCI patients in the present study, this artifact of abdominal expulsive contractions is not present. Hence, similar to the limb muscles, the force generated decreases in proportion to the velocity of the shortening of the muscle. Fitting et al ${ }^{25}$ showed that there is a linear relationship between mean $\mathrm{Vt} / \mathrm{Ti}$ and mean velocity of diaphragmatic shortening during tidal breathing in dogs. Previous investigators have shown that both in humans ${ }^{26,27}$ and in animals, ${ }^{28,29}$ the maximal inspiratory pressures decrease as inspiratory flow increases. As indicated by the results of a $30 \%$ lower $\Delta \mathrm{Pdi}_{\text {sniff }}$ compared to $\Delta \mathrm{Pdi}_{\max }$ in the present study, a dynamic contraction with shortening 
of the diaphragm is expected to generate lower forces than an isometric contraction. Miller et al. ${ }^{24}$ reported a tendency for a correlation between $\Delta \mathrm{Pdi}_{\text {sniff }}$ and $\Delta \mathrm{Pdi}_{\text {max }}$. In contrast, our study showed a high linear correlation between $\Delta \mathrm{Pdi}_{\max }$ and $\Delta \mathrm{Pdi}_{\text {sniff }}(r=0.79)$, where $\Delta \mathrm{Pdi}_{\text {sniff }}$ is proportional to, but lower than $\Delta \mathrm{Pdi}_{\max }$. In the transition region between these two dependencies, a linear regression following the equation, $\Delta \mathrm{Pdi}_{\text {sniff }}=-1.08+\Delta \mathrm{Pdi}_{\max } \times 0.76(P<$ 0.0001 ), describes the relation quite well. The dispersion of $\Delta \mathrm{Pdi}_{\text {sniff }}$ with respect to $\Delta \mathrm{Pdi}_{\max }$ among subjects was however high.

Forner ${ }^{30}$ reported an average $\mathrm{VC}_{\%}$ pred of $51 \%$ in 48 CCI patients injured at $\mathrm{C} 5-\mathrm{C} 8$ which is similar to the median values of $\mathrm{VC}_{\% \text { pred }}$ in the present study $(50 \%$ in the $\mathrm{CCI}_{1-3}$ group and $57 \%$ in the $\mathrm{CCI} \geqslant 10$ group). In the $\mathrm{CCI}$ and PPI patients, $\mathrm{VC}_{\% \text { pred }}$ was strongly dependent on $\Delta \mathrm{Pdi}_{\max }$ suggesting that the reduced VC is due to muscular impairment. A clear correlation between inspiratory muscle force and $\mathrm{VC}_{\% \text { pred }}$ has also been observed in patients with other neuromuscular disorders. ${ }^{1}$

In the present study there was a positive correlation between $\mathrm{VC}_{\% \text { pred }}$ and the levels of intercostal muscle function, as assessed with the EMG electrodes in the $\mathrm{CCI}_{1-3}$ patients. In the $\mathrm{CCI} \geqslant 10$ group, no such correlation was found. Estenne and De Troyer ${ }^{31}$ described that rib cage motion in CCI patients $(\mathrm{C} 4-$ C7), injured 4 months to 26 years previously and with no signs of inspiratory related intercostal muscle EMG activity, is dependent on the function of the accessory muscles. In general, they found that the lower rib cage expanded more than the upper. Paradoxical anteroposterior (AP) movements of the upper rib-cage dominated in these patients with silent or continuous spastic scalenes. In patients with functioning scalenes, no movement or small increases in the AP diameter were found. The authors also described two patients injured 9 and 26 years previously as having paradoxical upper chest wall AP movements. This was not found in two patients 3 and 5 months after injury. Still, no clear association between rib cage mechanics and time since injury has been established. De Troyer and Heilporn ${ }^{32}$ showed that longstanding paralysis (2.5 to 10 years) of intercostal muscles in CCI patients (C5-C7) resulted in marked alterations of lung compliance and a reduction in the passive outward recoil of the chest wall. Normal functional residual capacity and compliance of the respiratory system was found in only two patients with maintained inspiratory intercostal EMG activity. Thus, it seems that the activity of the intercostal and scalene muscles is important in preserving the respiratory mechanics during the first decade following injury.

Fugl-Meyer and Grimby ${ }^{33}$ reported a low correlation between lung volume and the clinically determined lesion level in $14 \mathrm{CCI}$ patients $(\mathrm{C} 4-\mathrm{C} 8)$ injured for less than 6 years. In our data, there was no such correlation in the CCI groups, whereas a low correlation between $\Delta \mathrm{Pdi}_{\max }$ and the motor level of injury was found in the $\mathrm{CCI} \geqslant 10$ group. These results imply that the motor level of injury is a weak predictor of the respiratory function in low cervical cord injuries (C5-C8).

The exercise test showed that PPI exer $_{\text {patients had }}$ no or modest increases in TTdi upon exertion. One patient even demonstrated a reduced TTdi from rest to the last minute of exercise. In the PPI ${ }_{\text {exer }}$ patients who increased their TTdi, the increase was mainly due to an increase in $\mathrm{Ti} / \mathrm{Ttot}$ and was associated with an increase in ventilation. In contrast, the $\mathrm{CCI}_{\text {exer }}$ patients had a substantial increase in TTdi from rest to the last minute of exercise with increases in ventilation similar to those found in $P P I_{\text {exer }}$ patients. In PPI ${ }_{\text {exer }}$ patients, shifts of the major axis in the Pes-Pga curve and increases in Pes denote a synergistic coordination of the inspiratory and expiratory muscles in order to increase ventilation (Figure 10). Despite the similarity in $\Delta \mathrm{Pdi} / \Delta \mathrm{Pdi}_{\max }$ values at rest and small or no increases in $\Delta \mathrm{Pdi} / \Delta \mathrm{Pdi}_{\max }$ during exercise in the $\mathrm{PPI}_{\text {exer }}$ group, those patients clearly perceived higher respiratory efforts during the pre-test. The divergent response to exercise in the $\mathrm{PPI}_{\text {exer }}$ group, with the perception of strenuous respiration, the inability to increase force, and the differences in ventilatory strategy, strongly suggests a reduced force reserve. However, it should be noted that the force reductions observed in kypho-scoliotic PPI patients is due to a combination of mechanical disadvantage and diaphragm paralysis. The earlier history of hypercapnic respiratory insufficiency in two of the PPI ${ }_{\text {exer }}$ patients having no or almost no increase in TTdi during the exercise is in accordance with previous findings that hypercapnia is preferred to respiratory muscle fatigue. $^{2} 6$

In summary, the major findings of this study are: (1) vital capacity is related to maximal inspiratory muscle force in CCI and PPI patients, (2) the static respiratory force parameters are similar in the recently and the long-time injured CCI groups, but lower in the PPI group, (3) the TTdi during breathing at rest is similar for all groups, (4) the PPI patients respond to intrinsic inspiratory loads with much smaller changes in TTdi than the CCI patients with similar $\Delta \mathrm{Pdi}_{\text {max }}, \Delta \mathrm{Pdi}_{\text {sniff, }}$ and resting TTdi. We speculate that preserved afferent neural pathways in PPI patients are responsible for the difference in inspiratory muscle output upon exertion.

\section{Acknowledgements}

This study was supported by grants from King Gustav V Foundation, the Swedish Association for Traffic and Polio Disabled, the Swedish Association for Neurologically Disabled, The Royal Wedding Foundation, Trygg Hansa Insurance Company, Glaxo group plc, Draco Inc. and The Greta and Einar Askers Research Foundation. 


\section{References}

1 Braun NMT, Arora NS, Rochester DF. Respiratory muscle and pulmonary function in polymyositis and other proximal myopathies. Thorax 1983; 38: 616-623.

2 Martyn JB, Moreno RH, Paré PD, Pardy RL. Measurement of inspiratory muscle performance with incremental threshold loading. Am Rev Respir Dis 1987; 135: 919-923.

3 Vincken W, Guilleminault C, Cosio M, Grassino A. Onset of diaphragmatic fatigue: a stimulus to terminate obstructive sleep apnea? Am Rev Respir Dis 1987; 135: 372 - 377.

4 Bazzy AR, Haddad GG. Diaphragmatic fatigue in unanaesthetized adult sheep. J Appl Physiol 1984; 57: 182-190.

5 Sadoul N, Bazzy AR, Akabas SR, Haddad GG. Ventilatory response to fatiguing and nonfatiguing resistive loads in awake sheep. J Appl Physiol 1985; 59: 969 -978.

6 Begin P, Grassino A. Inspiratory muscle dysfunction and chronic hypercapnia. Am Rev Respir Dis 1991; 143: 905-912.

7 Bellemare F, Grassino A. Effect of pressure and timing of contraction on human diaphragm fatigue. J Appl Physiol Respirat Environ Exercise Physiol 1982a; 53: 1190-1195.

8 Bellemare F, Grassino A. Evaluation of human diaphragm fatigue. J Appl Physiol Respirat Environ Exercise Physiol 1982b; 53: $1196-1206$.

9 Bedbrook G. Lifetime care of the paraplegic patient. Edinburgh: Churchill Livingstone. 1985.

10 Bach JR, Alba AS, Bohatiuk G, Saporito L, Lee M. Mouth intermittent positive pressure ventilation in the management of postpolio respiratory insufficiency. Chest 1987; 91: 859-864.

11 Bach JR, Alba AS, Shin D. Management alternatives for postpolio respiratory insufficiency. Assisted ventilation by nasal or oral-nasal interface. Am J Phys Med Rehabil 1989; 68: 264-271.

12 Curran FJ, Colbert AP. Ventilator management in Duchenne muscular dystrophy and postpoliomyelitis syndrome: twelve years experience. Arch Phys Med Rehabil 1989; 70: 180-185.

13 Javaheri S, Vinegar A, Smith J, Donovan E. Use of a modified Swan-Ganz pacing catheter for measuring Pdi and diaphragmatic EMG. Pflügers Arch 1987; 408: 642-645.

14 Latimer KE, Latimer RD. Measurements of pressure-wave transmission in liquid-filled tubes used for intravascular bloodpressure recording. Med \& Biol Engng 1969; 7: 143-168.

15 Milic-Emili J. P412 Measurement of pressures in respiratory physiology In: Techniques in respiratory physiology - part II. Techniques in the life sciences (ed). A.B. Otis. Elsevier scientific publishers Ireland Ltd, vol P4/II, 1984, pp 1-22.

16 Baydur A, Behrakis PK, Zin WA, Milic-Emili J. A simple method for assessing the validity of the esophageal balloon technique. Am Rev Respir Dis 1982; 126: 788 - 791.
17 Borg G, Noble BI. Perceived exertion. In: Exercise and Sport Sciences Reviews (ed). J. Wilmore, New York Academic Press, vol 2, 1974, pp 131-153.

18 Laporta D, Grassino A. Assessment of transdiaphragmatic pressure in humans. $J$ Appl Physiol 1985; 58: $1469-1476$.

19 Agostoni E, H. Rahn. Abdominal and thoracic pressures at different lung volumes. J Appl Physiol 1960; 15: 1087-1092.

20 Milic-Emili J, Orzalesi MM, Cook CD, Turner JM. Respiratory thoraco-abdominal mechanics in man. J Appl Physiol 1964; 19: $217-223$.

21 Moisan TC, Wicks MS, Druz WS, Sharp JT. Diaphragmatic function and body position in chronic obstructive pulmonary disease. Am Rev Respir Dis 1978; 117: 378.

22 De Troyer A, Estenne M. Limitations of measurement of transdiaphragmatic pressure in detecting diaphragmatic weakness. Thorax 1981; 36: 169-174.

23 Braun NMT, Arora NS, Rochester DF. Force-length relationship of the normal human diaphragm. J Appl Physiol 1982; 53: $405-412$.

24 Miller JM, Moxham J, Green M. The maximal sniff in the assessment of diaphragm function in man. Clin Sci 1985; 69: 91 96.

25 Fitting JW, Easton PA, Grassino AE. Velocity of shortening of inspiratory muscles and inspiratory flow. J Appl Physiol 1986; 60: $670-677$.

26 Agostoni E, Fenn WO. Velocity of muscle shortening as a limiting factor in respiratory airflow. J Appl Physiol 1960; 15: 349 .

27 Hyatt RE, Flath RE. Relationship of airflow to pressure during maximal respiratory effort in man. J Appl Physiol 1966; 21: 477.

28 Pengelly LD, Alderson AM, Milic-Emili J. Mechanics of the diaphragm. J Appl Physiol 1971; 30: 797-805.

29 Mognoni P, Saibene F, Sant' Ambrogio G, Agostoni E. Dynamics of the maximal contraction of the respiratory muscles. Respir Physiol 1968; 4: 193.

30 Forner JV. Lung volumes and mechanics of breathing in tetraplegics. Paraplegia 1980; 18: $258-266$.

31 Estenne M, De Troyer A. Relationship between respiratory muscle electromyogram and rib cage motion in tetraplegia. $\mathrm{Am}$ Rev Respir Dis 1985; 132: 53-59.

32 De Troyer A, Heilporn A. Respiratory mechanics in quadriplegia. The respiratory function of the intercostal muscles. $\mathrm{Am}$ Rev Respir Dis 1980; 122: 591 - 600.

33 Fugl Meyer AR, Grimby G. Ventilatory function in tetraplegic patients. Scand J Rehab Med 1971; 3: 151-163. 